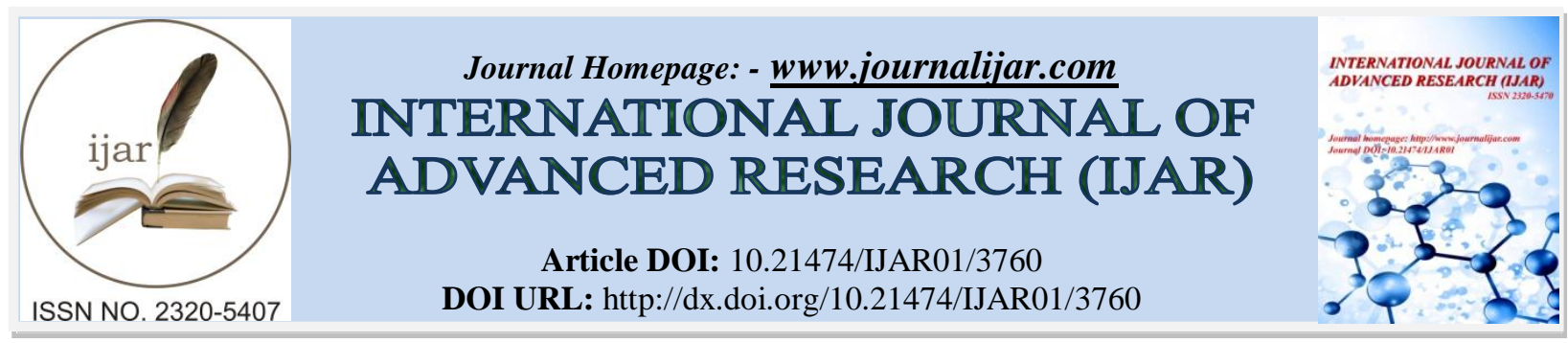

RESEARCH ARTICLE

\title{
EFFECT OF TRIDEX EXTRACT ON SEED GERMINATION BIOASSAY.
}

Sakdeo Babita Marutirao.

Department of Botany, Shardabai Pawar Mahila College, Affiliated to Savitribai Phule Pune University, Shardanagar, Tal. Baramati, Dist. Pune.

\section{Manuscript Info}

Manuscript History

Received: 16 January 2017

Final Accepted: 15 February 2017

Published: March 2017

Key words:-

Extract, concentration , Germination ,

Seedling, Cowpea ,Tridax

\section{Abstract}

The fully mature fresh leaves of Tridaxprocumbens L. were collected and prepared extract .Tridaxis weed, used for germination .Make different concentration of extract. This was carried on Cowpea vignaunguiculata $(\mathrm{L}$.) Walp . The studies on the influence of extract on seed germination are highly essential and of paramount importance, considering this view, the impact of Tridax leaf extract has been studied by using seed germination bioassay of Cowpea in the present investigation

Copy Right, IJAR, 2017,. All rights reserved.

\section{Introduction:-}

Cowpeas are one of the most important food legume crops in the semiarid tropics covering Asia, Africa, southern Europe, and Central and South America. A drought-tolerant and warm-weather crop, cowpeas are well-adapted to the drier regions of the tropics, where other food legumes do not perform well. It also has the useful ability to fix atmospheric nitrogen through its root nodules, and it grows well in poor soils with more than $85 \%$ sand and with less than $0.2 \%$ organic matter and low levels of phosphorus. In addition, it is shade tolerant, so is compatible as an intercrop with maize, millet, sorghum, sugarcane, and cotton. This makes cowpeas an important component of traditional intercropping systems, dried stalks of cowpea is a valuable by-product, used as animal feed.

Seed germination is one of the most basic aspects. During seed germination sequential series of physiological and biochemical event takes place in quiescent seed, resulting into seedling. It is transition period between resting and growth phases of plants and considered to be completed at the time of emergence of radical .The stimulatory or inhibitory impact of extract can be initially analysed through seed germination bioassay studies. Tridax leaf extract was used to study seed germination bioassay on Cowpea.

\section{Material And Method:-}

\section{Collection of material:-}

The fully mature fresh leaves were collected in polythene bags from the fixed study area and the material was brought to the laboratory in ice bags. Leaves were washed thoroughly under tap water and spread over the blotting papers under shade for drying.

\section{Preparation of Extracts:-}

Freshly collected mature leaves were cleaned and shade dried. The leaves were uniformly homogenized in $100 \mathrm{ml}$ $80 \%$ ethanol and condensed in water bath to $10 \mathrm{ml}$ below $60^{\circ} \mathrm{C}$ to avoid evaporation of volatile compounds and denaturation of active principle in it. This was filtered and filtrate was made to $100 \mathrm{ml}$ final volume with sterile distilled water \& stored in sterile coloured bottle in deep freezer at $0^{0} \mathrm{C}$ for further use. 


\section{Seed germination bioassay:-}

This is carried out with Cowpea. Uniform seeds were washed thoroughly in water \&surface sterilized with $0.5 \% \mathrm{Hgcl} 2$ solution \&again washed with distilled water. Surface sterilized seeds were germinated in different concentration of Tridax leaf extract observation on

(1)Germination \%

(2)Length of plumule\& radicle.

(3)Root/shoot ratio

(4)Fresh \& dry weight of seedling

(5)Vigor index were recorded. All the sets were triplicated under laboratory condition. Observation onthe following parameter were recorded.

\section{Germination percentage:-}

Development of seedling from seeds is known germination. It is a process in which the seed sprouts for growing \&developing into a plant. Germination percentage is a calculated approximately ofthe viability of a population at seeds. The germination rate provides a measure of the time course of seed germination.

Record for seeds germinated in each treatment from $2^{\text {nd }}$ day to $9^{\text {th }}$ days after sowing was noted carefully. The seeds with normal length of radicle \&plumule were considered as germinated seeds. The percent germination was calculated as

Germination percentage $=$ Number of seed germinated

Total number of seeds kept for germination

Length ofPlumule\& radicle in germinated seeds.

From each replication \&each replication andeach treatmentten germination seeds were randomly selected \& the length of selected Plumule $\&$ radicle of these germinating seeds was recorded at $6^{\text {th }} \& 9^{\text {th }}$ days.

\section{Root/shoot ratio -}

The root /shoot ratio for each germinating seeds at each treatment was calculated as follows

Root length $(\mathrm{cm})$

Root /Shoot Ratio =

$$
\text { Shoot length }(\mathrm{cm})
$$

\section{Seed Vigor index (VI):-}

Seedling vigor index were determined by germination percentage and seedling length of the same seed lot .Seed vigor index is calculated by multiplying germination \%\& Seedling length.

Seed vigor index $=$ germination $\%$ Xseedling length $(\mathrm{mm})$

Table 1:-

\begin{tabular}{|c|c|c|c|c|c|c|c|}
\hline Sr.no & Extract (\%) & $\begin{array}{l}\text { \% } \\
\text { germination }\end{array}$ & $\begin{array}{l}\text { Shoot length } \\
\text { (cm) }\end{array}$ & $\begin{array}{l}\text { Root } \\
\text { length } \\
\text { (cm) }\end{array}$ & $\begin{array}{c}\text { Total } \\
\text { length } \\
(\mathbf{c m}) \\
\end{array}$ & $\begin{array}{l}\text { Root/shoot } \\
\text { Ratio } \\
\text { ( cm ) }\end{array}$ & $\begin{array}{l}\text { Vigor } \\
\text { Index(VI) }\end{array}$ \\
\hline 1 & Control & $60 \%$ & 2.3 & 11.5 & 13.8 & 5.0 & 828 \\
\hline 2 & $1 \%$ & $80 \%$ & 9.9 & 10.5 & 21.4 & 0.15 & 1712 \\
\hline 3 & $2 \%$ & $90 \%$ & 10.5 & 12.1 & 21.0 & 1.15 & 1890 \\
\hline 4 & $3 \%$ & $100 \%$ & 12.00 & 14.0 & 24.1 & 1.16 & 2410 \\
\hline 5 & $4 \%$ & $100 \%$ & 12.8 & 9.9 & 26.8 & 0.77 & 2680 \\
\hline 6 & $5 \%$ & 70\% & 8.00 & 11.5 & 17.9 & 1.43 & 1432 \\
\hline
\end{tabular}



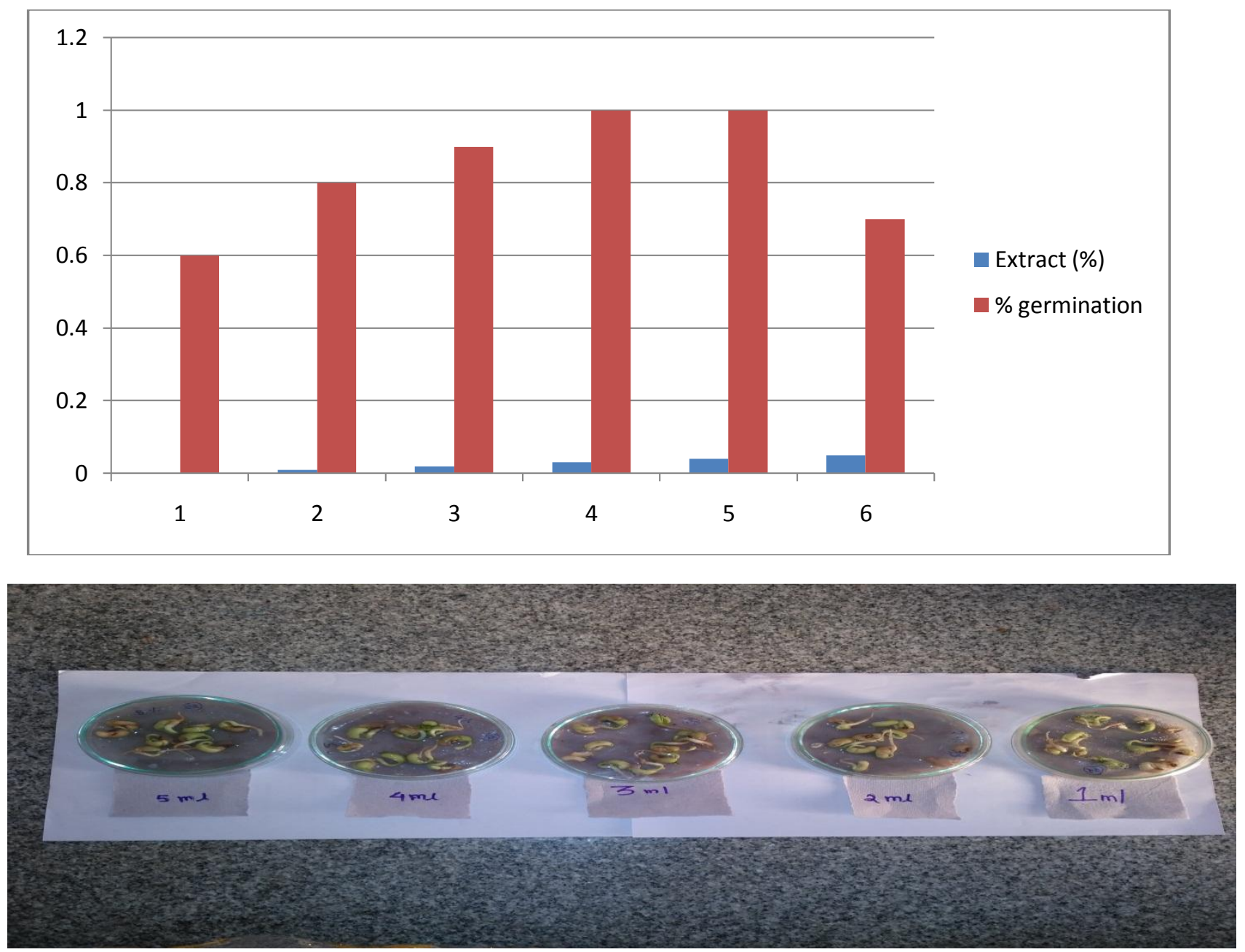

\section{Result And Discussion:-}

Effects of extracts on seeds germination:-

The result recorded in table 1 indicate that theextracts had positively stimulated the seed germination percentage over control in higher concentration. While the lower conc. (1\%,2\% 3\%) have caused low influence on seed germination. The length of root \& shoot was significantly increased at $4 \%$ concentration, however at lower conc. it was reduced over control.

\section{Root / shoot length:-}

In present investigation the impact of the extracts on root \& shoot length in Cowpea seedling was studied in details. For this extracts of (Tridax) were used. From the result it is seen that extract of the species was stimulatory enhancing the seed germination at higher conc. (4\%) however lower concentration adversely affected the seed germination, root length \& shoot length.

\section{Seed vigor index (VI)-}

4\% Tridaxextract seed lotshowing the higher seed vigor index is considered to be more vigorous.

\section{Conclusion:-}

The early seedling growth governsits establishment thought root \& shoot elongation. The uptake of water \& nutrients depends on the early root development $\&$ its spreading. Inhibitionor stimulation of root $\&$ shoot length at seedling level will have adverse or favorable effects on the future growth of the plant. 


\section{References:-}

1. Dubey P.S. (1973) .Phytotoxicity of weeds to crops effect on germination. Sci and cult

2. 39: $556-558$

3. Peswani.K.M (1981) .seed farms 7 (2);11-15

4. Singh R.R \& K.S chouhan\& H.K Singh(1989) .effect various does of N.P \& K on physiochemical composition of ber fruits cv.Gola. Prog. Hort. 18 (1-2); 35 -38

5. Narwal S.S, K.Gupta\& S.S Pahuja (1990). Indian J. Ecol. 17;174

6. Prabha. R 1990. Controversial correlation in ayurvedicdrugs ,Amruth; benefiting from biodiversity. Magazine on medicinal plants .FRLTH publication 3;1-12.

7. OKpuzar J \&Omidiji O. 1998. Peroxidase - polyphenol oxidase association in Dioscoriaesciulanta. Z. Naturforsch 53;957-960.

8. Khan P.A., Mughal A.H. and khan M.A. ( 2001). Alleopathic effects of Populus deltoids M. on germination \&seedling growth of some vegetable range management \& agro forestry . 22; 231- 236.

9. Mahadik S.G \&B .B jadhav (2003) influence of kokum (Garciniaindica.Choisy.)\&gulmohor (DelonixregiaRaffin) leaf leachates on germination of rice \& Cowpea. In ;second international congress of plant physiology . pp-292.

10. C.S .Yusuf, N. Makate\& R. Jacob (10 octo 2014) International Journal of scientific \& Research publication, Volum 4,issue. Effect of seed size on germination \& early growth of maize (Zea mays). 